\title{
PENGARUH KARAKTERISTIK ORGANISASI DAN BUDAYA ORGANISASI TERHADAP KOMITMEN MANAJERIAL, KEPERCAYAAN ANGGOTA DAN PARTISIPASI ANGGOTA SERTA DAMPAKNYA PADA KINERJA KOPERASI PADA KOPERASI KREDIT (CREDIT UNION) DI FLORES
}

\author{
Oleh
}

Dr. Hyronimus Se, MM

Dosen Program Studi Manajemen

e-mail: hyronimus_odjase@yahoo.com

\begin{abstract}
ABSTRAK
Penelitian ini bertujuan untuk menganalisis pengaruh karakteristik organisasi dan budaya organisasi terhadap komitmen manajerial, kepercayaan anggota, dan partisipasi anggota, dampaknya terhadap kinerja koperasi pada Koperasi Simpan Pinjam di Pulau Flores, Provinsi Nusa Tenggara Timur, Indonesia. Populasi dalam penelitian ini adalah pengurus, pengawas, dan pengelola seluruh credit unions yang ada di Flores. Jumlah sampel sebanyak 237 responden diperoleh dengan menggunakan teknik simple random sampling. Teknik analisis data menggunakan Structural Equation Model (SEM) dengan konsep dan aplikasi menggunakan program Analysis of Moment Strucues (AMOS) versi 21. Hasil penelitian menunjukkan bahwa: (1) karakteristik organisasi berpengaruh signifikan terhadap komitmen manajerial dan partisipasi anggota, (2) organisasi budaya berpengaruh signifikan terhadap komitmen manajerial, kepercayaan anggota, dan partisipasi anggota, (3) komitmen manajerial berpengaruh signifikan terhadap kinerja koperasi, (4) kepercayaan anggota berpengaruh signifikan terhadap kinerja koperasi, (5) partisipasi anggota berpengaruh signifikan berpengaruh terhadap kinerja koperasi.
\end{abstract}

Kata Kunci: Karakteristik organisasi, budaya organisasi, kepercayaan anggota, partisipasi anggota, kinerja koperasi.

\section{ABSTRACT}

This study aims to analyze the influence of organizational characteristics and organizational culture on managerial commitment, member trust, and member participation, the impact on the performance of cooperatives in credit unions in Flores, East Nusa Tenggara Province, Indonesia. The population in this study included administrators, supervisors, and managers of all credit unions in Flores. The total sample of 237respondents was obtained by using the simple random sampling technique. Data analysis techniques usingStructural Equation Model (SEM) with concepts and applications using Analysis of Moment Strucues (AMOS) program version 21. The results of the study show that: (1) organizational characteristics significantly influence managerial commitment and member participation, (2) organizational culture has a significantly effect on managerial commitment, member trust, and member 
PENGARUH KARAKTERISTIK ORGANISASI DAN BUDAYA ORGANISASI TERHADAP KOMITMEN MANAJERIAL, KEPERCAYAAN ANGGOTA DAN PARTISIPASI ANGGOTA SERTA DAMPAKNYA PADA KINERJA KOPERASI PADA KOPERASI KREDIT (CREDIT UNION) DI FLORES-Hyronimus Se

participation, (3) managerial commitment has a significantly effect on cooperative performance, (4) member trust has a significantly effect on cooperative performance, (5) member participation has a significantly effect on performance cooperative.

Key Words: Organizational characteristics, organizational culture, member trust, member participation, cooperative performance.

\section{Pendahuluan}

Dalam Undang-Undang No. 25 Tahun 1992 tentang pokok-pokok perkoperasian dinyatakan bahwa koperasi sebagai ekonomi rakyat bertujuan untuk memajukan kesejahteraan anggota pada khususnya dan masyarakat pada umumnya serta ikut membangun tatanan perekonomian nasional dalam rangka mewujudkan masyarakat yang maju, adil dan makmur berlandaskan Pancasila dan Undang-Undang Dasar 1945 berdasar atas asas kekeluargaan. Koperasi berperan positif dalam pelaksanaan pembangunan nasional di Indonesia, baik secara langsung maupun tidak langsung. Koperasi merupakan sarana peningkatan kemajuan ekonomi bagi anggotanya dan bagi masyarakat. Hal ini sesuai dengan tujuan koperasi, khususnya untuk memajukan kesejahteraan anggota dan masyarakat pada umumnya.

Menurut Sukijo (2008) konsep koperasi merupakan konsep yang sifatnya general, namun koperasi Indonesia mempunyai karakteristik yang berbeda dengan koperasi di negara lain. Koperasi tidak sekedar badan usaha tetapi koperasi Indonesia merupakan agen pembangunan untuk pengentasan kemiskinan, meningkatkan kesejahteraan masyarakat, dan berperan untuk menyebarluaskan jiwa dan semangat koperasi. Namun demikian, rendahnya kualitas SDM koperasi, adanya kasus-kasus penyimpangan, serta kurang optimalnya peran pengawas menyebabkan kinerja koperasi semakin terpuruk sehingga masyarakat trauma dan memiliki persepsi yang negatif terhadap koperasi. Munandar (2004) menjelaskan komitmen manajer dibagi dalam tiga komponen, yaitu: (1) komponen aktif yang berkaitan dengan emosional, identifikasi, dan keterlibatan pegawai didalam suatu organisasi, (2) komponen normatif merupakan perasaan pegawai tentang kewajiban yang harus diberikan kepada organisasi, dan (3) komponen continuance berarti komponen yang berdasarkan persepsi pegawai tentang kerugian yang akan dihadapinya jika meninggalkan organisasi. Mayer, Davis, dan Schoorman (1995) menjelaskan bahwa kepercayaan merupakan bagian inti dari sebuah organisasi karena didalam organisasi terdapat risiko dan saling ketergantungan sehingga sebuah rasa kepercayaan sangat dibutuhkan. 
PENGARUH KARAKTERISTIK ORGANISASI DAN BUDAYA ORGANISASI TERHADAP

KOMITMEN MANAJERIAL, KEPERCAYAAN ANGGOTA DAN PARTISIPASI ANGGOTA SERTA DAMPAKNYA PADA KINERJA KOPERASI PADA KOPERASI KREDIT (CREDIT UNION) DI FLORES-Hyronimus Se

Dalam organisasi koperasi anggota yang satu akan lebih percaya atas apa yang dikatakan oleh anggota lain atau anggota terdahulu mengenai informasi terkait perkembangan koperasi, manajemen, pengurus dan produk-produk pinjaman.

Sejak awal koperasi diperkenalkan di Indonesia memang diarahkan untuk berpihak pada kepentingan rakyat yang dikenal sebagai golongan ekonomi lemah. Koperasi kredit dinilai mampu dalam mengatasi kemiskinan dan menciptakan lapangan usaha. Dengan hadirnya koperasi kredit masyarakat sungguh dibantu karena di samping bunga pinjaman rendah, juga prosesnya sangat mudah.

Koperasi kredit di Flores-Provinsi Nusa Tenggara Timur mengalami perkembangan yang sangat pesat namun demikian pertumbuhan koperasi yang sangat banyak tidak diikuti kualitas dari koperasi kredit itu sendiri sehingga banyak koperasi kredit yang sangat sulit berkembang bahkan mati dalam waktu yang cepat. Koperasi kredit disatu sisi terdapat kemudahan dalam pendirian, namun disisi lain sangat dibatasi oleh ketentuan-ketentuan koperasi yang membuat koperasi kredit sangat sulit berkembang.

Tabel 1.1

Jumlah Koperasi Provinsi Nusa Tenggara Timur

Tahun 2013-2016

\begin{tabular}{|c|l|c|c|c|c|}
\hline \multirow{2}{*}{ No. Kabupaten / Kota } & \multicolumn{4}{c|}{ Tahun } \\
\cline { 3 - 5 } & & $\mathbf{2 0 1 3}$ & $\mathbf{2 0 1 4}$ & $\mathbf{2 0 1 5}$ & $\mathbf{2 0 1 6}$ \\
\hline 1. & Sumba Barat & 67 & 68 & 124 & 113 \\
\hline 2. & Sumba Timur & 95 & 98 & 117 & 153 \\
\hline 3. & Kupang & 268 & 261 & 357 & 327 \\
\hline 4. & Timor Tengah Selatan & 115 & 112 & 136 & 149 \\
\hline 5. & Timor Tengah Utara & 82 & 77 & 88 & 103 \\
\hline 6. & Belu & 179 & 123 & 146 & 149 \\
\hline 7. & Alor & 112 & 102 & 152 & 165 \\
\hline 8. & Lembata & 58 & 86 & 109 & 107 \\
\hline 9. & Flores Timur & 175 & 155 & 197 & 186 \\
\hline 10. & Sikka & 133 & 127 & 163 & 156 \\
\hline 11. & Ende & 105 & 101 & 141 & 142 \\
\hline 12. & Ngada & 92 & 99 & 119 & 116 \\
\hline 13. & Manggarai & 86 & 118 & 149 & 164 \\
\hline 14. & Rote Ndao & 155 & 148 & 186 & 177 \\
\hline 15. & Manggarai Barat & 94 & 111 & 141 & 135 \\
\hline 16. & Sumba Tengah & 26 & 31 & 50 & 49 \\
\hline 17. & Sumba Barat Daya & 42 & 71 & 115 & 144 \\
\hline 18. & Nagekeo & 42 & 56 & 89 & 89 \\
\hline 19. & Manngarai Timur & 42 & 38 & 106 & 99 \\
\hline 20. & Sabu Raijua & 21 & 24 & 32 & 46 \\
\hline 21. & Malaka & - & 72 & 111 & 125 \\
\hline 22. & Kota Kupang & $\mathbf{2 4 8 5}$ & $\mathbf{2 5 3 6}$ & $\mathbf{3 3 9 4}$ & $\mathbf{3 4 1 4}$ \\
\hline Jumlahy & & 458 & 566 & 520 \\
\hline
\end{tabular}

Sumber : Dinas Koperasi dan UKM Prov. NTT, 2016 
Dalam laporan yang dirilis Dinas Koperasi dan Usaha Kecil Menengah Provinsi Nusa Tenggara Timur pada tahun 2013 hingga 2016 jumlah koperasi yang terdaftar sebanyak 2.485, koperasi berkembang menjadi 3.414 koperasi di tahun 2016 dengan jumlah tenaga kerja yang terserap dari 4.658 orang menjadi 6.477 orang.

Setiap anggota koperasi kredit sadar akan kewajibannya sehingga orang lain mendapat kesempatan untuk memperoleh pinjaman. Tabel 1.2 menunjukkan data keanggotaan dan aset koperasi kredit di Flores adalah sebagai berikut :

Tabel 1.2

Data Keanggotaan dan Aset Koperasi Kredit di Flores

\begin{tabular}{|c|l|c|c|c|c|r|r|r|}
\hline No. & Nama Puskopdit & $\begin{array}{c}\text { Jumlah } \\
\text { Kopdit }\end{array}$ & $\begin{array}{c}\text { Jumlah } \\
\text { Anggota }\end{array}$ & $\begin{array}{c}\text { Menga } \\
\text { dakan } \\
\text { RAT }\end{array}$ & $\begin{array}{l}\text { Tidak } \\
\text { Mengadak } \\
\text { an RAT }\end{array}$ & Saham & $\begin{array}{c}\text { Non } \\
\text { Saham }\end{array}$ & Aset \\
\hline 1. & Swadaya Utama & 46 & 303.337 & 18 & 28 & 520 & 527 & 1,332 \\
\hline 2. & Flores Mandiri & 45 & 117.153 & 20 & 25 & 240 & 586 & 1.027 \\
\hline 3. & Manggarai Raya & 38 & 43.271 & 14 & 24 & 85 & 38 & 162 \\
\hline \multicolumn{2}{|r|}{ Jumlah } & 129 & 420.909 & 52 & 77 & 845 & 1.151 & 2.521 \\
\hline
\end{tabular}

(dalam milyar rupiah)

Sumber : Majalah Picu, 2016

Melihat pertumbuhan koperasi kredit di Flores memiliki potensi yang sangat besar bagi koperasi kredit yang tidak melakukan RAT secara rutin setiap tahun sehingga perlu dilakukan pembenahan sistem keuangannya. Penyelenggaraan RAT secara kontinyu dan tepat waktu akan memberikan nilai positif atas keberadaan koperasi kredit. Laporan keuangan yang dipertanggungjawabkan secara rutin setiap tahun oleh pengelola kepada pengurus, badan pengawas dan anggota/calon anggota koperasi kredit akan menambah kepercayaan anggota/calon anggota dan pemerintah. Koperasi yang tidak pernah menyelenggarakan RAT pertanda koperasi tersebut sudah mati suri. Penyebab koperasi kredit yang tidak melakukan RAT, salah satunya adalah koperasi kredit tersebut tidak dikelola secara efektif dan efisien.

\section{Kajian Pustaka}

\subsection{Karakteristik Organisasi}

Setiono (2001) mengungkapkan bahwa karakteristik organisasi merupakan kondisi internal dalam suatu organisasi dan merupakan ciri khusus yang membedakan antara organisasi satu dengan organisasi lainnya. 
Karakteristik yang dimaksud adalah (1) struktur organisasi yang mempunyai unsur pembagian kerja, departemenalisasi, hierarki, dan koordinasi, (2) budaya organisasi yang mempunyai unsur nilai yang mendukung, dan asumsi dasar. Simamora (1999) menyatakan bahwa karakteristik organisasi merupakan faktor-faktor lingkungan kerja individu. Hellriegel dan Slocum (1996) mengemukakan tentang praktek-praktek organisasi adalah aturan, kebijakan sumber daya manusia, praktek manajerial dan sistem ganjaran dalam suatu organisasi. Sedangkan Ting dan Yuan (1997) berpendapat bahwa karakteristik organisasi meliputi komitmen organisasi dan hubungan teman sekerja dan supervisor yang akan berpengaruh terhadap kepuasan kerja. Gerlof (1998) mengemukakan karakteristik dari sebuah organisasi yaitu tujuan, orang dan rencana.

\subsection{Budaya Organisasi}

Menurut Hofstede at.al (1990), budaya bukanlah perilaku yang jelas atau benda yang dapat terlihat dan diamati seseorang. Budaya juga bukanlah falsafah atau sistem nilai yang diucapkan atau ditulis dalam anggaran dasar organisasi tetapi budaya adalah asumsi yang terletak dibelakang nilai dan menentukan pola perilaku individu terhadap nilai-nilai organisasi, suasana organisasi dan kepemimpinan. Robbins (2006) mendefinisikan budaya organisasi adalah sistem makna bersama yang dianut oleh anggota-anggota yang membedakan organisasi itu dari organisasi lainnya. Terdapat unsur dalam pengertian budaya perusahaan/korporasi terdiri atas: sistem nilai, lingkungan bisnis, jaringan budaya, pola ritual keyakinan, nilai dan perilaku, gaya manajemen, sistem dan prosedur manajemen, norma-norma dan prosedur serta pedoman perilaku. Mas'ud (2004), budaya organisasi selanjutnya menjadi identitas atau karakter utama organisasi yang dipelihara dan dipertahankan. Amstrong (1994), budaya organisasi dapat digambarkan sebagai nilai, norma dan artefak yang diterima oleh anggota organisasi sebagai iklim organisasi ia akan memengaruhi dan dipengaruhi strategi organisasi, struktur dan sistem organisasi. Schein (1991) menyatakan bahwa budaya organisasi adalah pola asumsi dasar bersama yang dipelajari oleh kelompok saat memecahkan masalah-masalah adaptasi ekstern dan integarasi internal yang telah berfungsi dengan cukup baik untuk bisa diajarkan kepada anggota kelompok baru sebagai cara yang benar untuk menerima sesuatu, berpikir dan merasakan dalam hubungannya dengan masalah-masalah tersebut. 
Budaya organisasi menurut Cheki (2006) adalah seperangkat norma, persepsi, pola perilaku yang diciptakan atau dikembangkan dalam sebuah organisasi untuk mengatasi asumsi atau pandangan dasar yang diyakini karena telah berjalan baik dalam organisasi. Collins \& Porras (2000) mendefinisikan budaya organisasi sebagai kumpulan tradisi, nilai, kepercayaan, kebijakan, dan sikap yang merupakan konteks yang luas. Luthans (2006), budaya organisasi merupakan norma-norma dan nilai-nilai yang mengarahkan perilaku anggota organisasi.

\subsection{Komitmen Manajerial}

Steers (2002) mendefinisikan komitmen sebagai sifat hubungan dengan organisasi. Menurut Baron dan Greenberg (dalam Meyer dan Allen, 1997) mengemukakan bahwa komitmen memiliki arti penerimaan yang kuat individu terhadap tujuan dan nilai-nilai perusahaan, dimana individu akan berusaha dan berkarya serta memiliki hasrat yang kuat untuk tetap bertahan di perusahaan tersebut, maka dengan keduanya akan menimbulkan keberhasilan dalam pencapaian tujuan dari organisasi dengan baik. Menurut Mulins (1999) mengemukakan tiga proses atau tahap komitmen yaitu: (1) kebutuhan, dimana sesorang menerima pengaruh dari orang lain terhadap sesuatu yang diperoleh dari orang lain, (2) identifikasi, dimana individu menerima pengaruh untuk mempertahankan hubungan yang memuaskan dan merasa bangga dengan keberadaan organisasi atau perusahaan, dan (3) internalisasi, dimana individu menemukan nilainilai organisasi secara intrinsik, bermanfaat dan sesuai dengan nilai-nilai pribadi. Menurut Moekijad (dalam Pabundu Tika, 2014) menyatakan bahwa manajer adalah seseorang dalam suatu organisasi yang bertanggung jawab atas hasil kerja seorang bawahan atau lebih. Gasperz (2002), manajer berkualitas adalah manajer yang mempunyai kepemimpinan diri dan mampu membangun kepemimpinan tim. Komitmen manajerial dikembangkan McKisney \& Company, sebuah group konsultan dengan model komitmen yang disebut the five the commitments model yang menyebutkan bahwa para manajer yang unggul dapat menciptakan kesan yang kuat dan positif dari orang lain karena menggabungkan serangkaian keyakinan yang positif dengan perilaku yang positif pula 
PENGARUH KARAKTERISTIK ORGANISASI DAN BUDAYA ORGANISASI TERHADAP

KOMITMEN MANAJERIAL, KEPERCAYAAN ANGGOTA DAN PARTISIPASI

ANGGOTA SERTA DAMPAKNYA PADA KINERJA KOPERASI PADA KOPERASI

KREDIT (CREDIT UNION) DI FLORES-Hyronimus Se

\subsection{Kepercayaan Anggota}

Jhonson (2006) menyatakan kepercayaan (trust) merupakan dasar dalam membangun dan mempertahankan hubungan intrapersonal, dengan hubungan intrapersonal yang baik tentunya akan menjadi peluang yang besar dalam menjalin kelekatan dan dukungan sosial antara karyawan kepada organisasi. Morgan dan Hunt (1994), kepercayaan terjadi ketika seseorang yakin dengan reliabilitas dan integritas dari orang yang dipercaya. Kepercayaan menurut Robins dan Judge (2007) adalah suatu pengharapan positif bahwa pihak lain tidak akan bertindak oportunistik yang merujuk pada resiko di dalam hubungan antar manusia dan mungkin merupakan konsep yang kurang dimengerti ditempat kerja atau rasa percaya yang dimiliki orang terhadap orang lain. Sedangkan McShane dan Von Glinov (2008), kepercayaan menunjuk pada suatu pengharapan positif seseorang terhadap orang lain pada suatu situasi yang melibatkan resiko. Kepercayaan juga berarti menyerahkan nasib pada seseorang atau kelompok lain. Mayer (dalam Jasfar, 2009) menyatakan bahwa indikator kepercayaan terdiri dari tiga komponen yaitu integritas, kebaikan, dan kompetensi.

\subsection{Partisipasi Anggota}

Anoraga dan Nanik (2003), partisipasi anggota merupakan kesediaan anggota itu untuk memikul kewajiban dan menjalankan hak keanggotaannya secara bertanggung jawab. Jika sebagian besar anggota koperasi sudah melaksanakan kewajiban dan melaksanakan hak secara bertanggung jawab, maka partisipasi anggota yang bersangkutan sudah dikatakan baik. Castilo (dalam Jochen, 2003), partisipasi anggota sering disebut sebagai alat pengembangan maupun sebagai tujuan akhir itu sendiri. Winardi (2008) menyatakan bahwa partisipasi anggota adalah turut sertanya seseorang baik secara mental maupun emosional untuk memberikan sumbangan terhadap proses pembuatan keputusan, terutama mengenai persoalan-persoalan dimana keterlibatan pribadi yang bersangkutan melaksanakan tanggung jawabnya melakukan hal tersebut. Widiyanti (2004) mengemukakan partisipasi anggota dapat diukur dari kesediaan anggota untuk memiliki kewajiban dalam menjalankan hak keanggotaannya secara bertanggung jawab, dengan demikian maka partisipasi anggota dapat dikatakan baik. Menurut Ropke (2003) menyatakan bahwa partisipasi merupakan suatu proses dimana sekelompok orang (anggota) menemukan dan mengimplementasikan ide-ide dan gagasan koperasi. 
Partisipasi anggota merupakan hasil interaksi dari tiga variabel utama yaitu the members of beneficiaries, the management of organization, and the program. Sagimum (dalam Ninik Widiyanti, 2012) menyatakan koperasi adalah suatu alat untuk memperbaiki kehidupan berdasarkan tolong menolong diri sendiri dan auto activitieit dalam bentuk kerja sama. Hal ini menunjukkan koperasi itu diperlukan partisipasi anggota, artinya anggota itu berpartisipasi untuk anggota itu sendiri.

\subsection{Kinerja Koperasi}

Aldac dan Stearns (1987), kinerja adalah bahwa harus dipikirkan secara luas. Oleh karena itu kinerja yang hanya difokuskan pada kuantitas output akan disayangkan. Menurut Peter F. Drucker (1993) menyatakan definisi kinerja adalah tingkat prestasi (karya) atau hasil nyata yang dicapai yang juga kadang-kadang dipergunakan untuk mencapai suatu hasil yang positif. Menurut Stoner dan Freeman (dalam Andri (2003) memberikan penjelasan mengenai kinerja organisasi sebagai the measure of how well organization do their njob. Jadi kinerja perusahaan dapat diartikan sebagai hasil yang telah dicapai atas aktivitas yang dilakukan perusahaan. Menurut Mangkunegara (2000) kinerja merupakan derajat penyusunan tugas yang mengatur pekerjaan seseorang. Kinerja adalah keadilan kesediaan seseorang atau kelompok orang untuk melakukan kegiatan atau menyempurnakannya sesuai dengan tanggung jawab dengan hasil seperti yang diharapkan. Abdulah (2005), sebagai lembaga keuangan mikro non bank, koperasi kredit dapat melakukan kegiatan-kegiatan keuangan mikro (mikro finance) yakni penyedia jasa keuangan bagi anggotanya. Ropke (1996) menyatakan tujuan didirikannya koperasi antara lain untuk mencapai suatu usaha (business success), sukses pengembangan koperasi (development success of cooperative), dan sukses keanggotaan koperasi (member's success of cooperative). 


\subsection{Kerangka Konsep}

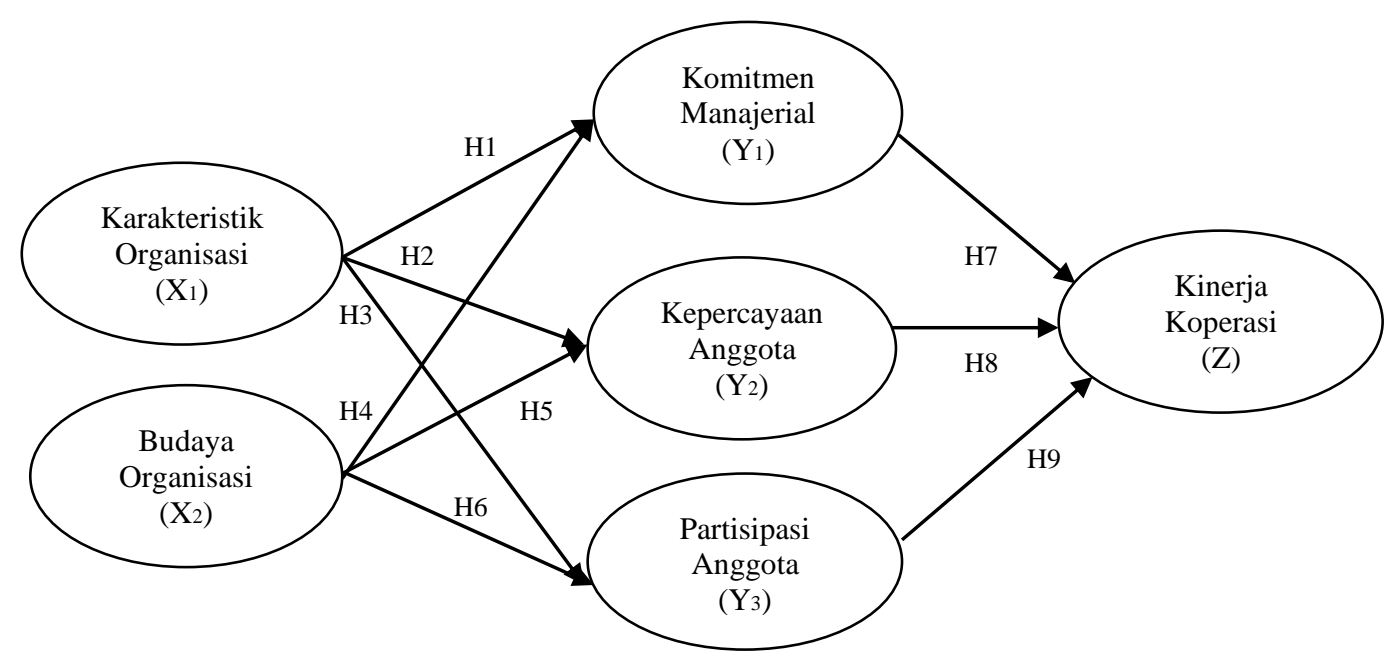

Gambar kerangaka konsep diatas menjelaskan hubungan antara variabel dengan variabel intervening sebagai variabel yang menghubungkan antara variabel independen dengan variabel dependen.

\subsection{Hipotesis Penelitian}

Berdasarkan latar belakang, rumusan masalah, tujuan penelitian, telaah pustaka, dan kerangka konseptual yang telah dikemukakan, maka dapat disusun hipotesis penelitian sebagai berikut:

1. Karakteristik organisasi memiliki pengaruh signifikan dan positif terhadap komitmen manajerial pada koperasi kredit (credit union) di Flores.

2. Karakteristik organisasi memiliki pengaruh signifikan dan positif terhadap kepercayaan anggota pada koperasi kredit (credit union) di Flores.

3. Karakteristik organisasi memiliki pengaruh signifikan dan positif terhadap partisipasi anggota pada koperasi kredit (credit union) di Flores.

4. Budaya organisasi memiliki pengaruh signifikan dan positif terhadap komitmen manajerial pada koperasi kredit (credit union) di Flores.

5. Budaya organisasi memiliki pengaruh signifikan dan positif terhadap kepercayaan anggota pada koperasi kredit (credit union) di Flores.

6. Budaya organisasi memiliki pengaruh signifikan dan positif terhadap partisipasi anggota pada koperasi kredit (credit union) di Flores. 
7. Komitmen manajerial memiliki pengaruh signifikan dan positif terhadap kinerja koperasi pada koperasi kredit (credit union) di Flores.

8. Kepercayaan anggota memiliki pengaruh signifikan dan positif terhadap kinerja koperasi pada koperasi kredit (credit union) di Flores.

9. Partisipasi anggota memiliki pengaruh signifikan dan positif terhadap kinerja koperasi pada koperasi kredit (credit union) di Flores.

\section{Metode Penelitian}

\subsection{Subjek Penelitian}

Populasi dalam penelitian ini adalah pengurus, pengawas, dan pengelola dari seluruh koperasi kredit (credit union) yang berlokasi di Flores-Provinsi Nusa Tenggara Timur. Populasi yang terjangkau meliputi koperasi kredit yang berkantor di Flores yang tercatat pada Dinas Koperasi dan Usaha Kecil Menengah Provinsi Nusa Tenggara Timur dan Induk Koperasi Kredit. Populasi target/jumlah pada penelitian ini adalah 584 orang. Jumlah sampel penelitian sebanyak 237 responden. Teknik analisis data yang terkumpul dianalisa secara statistik menggunakan analisis Structural Equation Model (SEM) dengan konsep dan aplikasi mengunakan program Analysis of Moment Strucues (AMOS) versi 21. Metode sampling yang dipergunakan dalam penelitian ini adalah probability sampling dimana teknik sampling ini memberikan peluang yang sama bagi setiap unsur (anggota) populasi untuk dipilih menjadi anggota sampel.

\subsection{Lokasi Penelitian}

Penelitian mengenai karakteristik organisasi, budaya organisasi, komitmen manajerial, kepercayaan anggota, partisipasi anggota terhadap kinerja koperasi di 9 (sembilan) koperasi kredit (credit union) di Flores - Provinsi Nusa Tenggara Timur. Waktu Penelitian dan pengambilan sampel dilakukan pada tahun 2018-2019. 


\subsection{Metode Pengumpulan Data}

Untuk mendapatkan data yang diperlukan dalam penelitian ini dilakukan dengan cara sebagai berikut:

1. Wawancara

Wawancara merupakan teknik pengumpulan data yang dilakukan melalui tatap muka dan tanya jawab langsung antara pengumpul data maupun peneliti terhadap narasumber atau sumber data.

2. Kuesioner

Kuesioner adalah teknik pengumulan data yang dilakukan dengan cara memberikan seperangkat pertanyaan atau pernyataan kepada responden, dengan harapan mereka akan memberikan respon / jawaban atas daftar pertanyaan tersebut.

3. Dokumentasi

Teknik pengumpulan data yang dilakukan dengan menggali informasi lewat fakta yang tersimpan dalam bentuk surat kabar, arsip, foto, sisa hasil usaha dan hasil rapat yang terjadi pada masa silam.

\subsection{Metode Analisis Data}

Berkaitan dengan rumusan masalah dan tujuan penelitian, maka teknik analisa data yang dipergunakan adalah metode kuantitatif dengan cara analisa data menggunakan uji statistik. Teknik analisa data dengan cara menjelaskan, mendiskripsikan dan menggambarkan hubungan antara dua variabel atau lebih yang sudah dikumpulkan dengan landasan teori melalui uraian-uraian sistematis dan logis.

Teknik analisis data yang telah terkumpul akan dianalisa secara statistik menggunakan analisis Structural Equation Model dengan konsep dan aplikasi mengunakan program Analysis of Moment Strucues versi 21. Model persamaan struktural Analysis of Moment Strucues juga merupakan pendekatan yang terintegrasi antara analisis data dan kontruksi.Peneliti dapat melakukan pengujian model (struktur hubungan variabel) yang ada justifikasi teoritisnya ataupun pengembangan baru (Supranto, 2004). Salah satu tujuan menggunakan Analysis of Moment Strucues adalah menyediakan estimasi-estimasi yang paling baik terhadap parameter-parameter yang berfariasi didasarkan dengan meminimalkan fungsi yang melakukan indeks seberapa baik model-model, serta dikenakan kendali-kendali yang sudah diidentifikasi terlebih dahulu. 


\subsection{Instrumen Pengumpulan Data}

Untuk mendukung sumber informasi, pengambilan data dalam penelitian ini dilakukan melalui personality administered questonaires sehingga memungkinkan peneliti berhubungan langsung dan memberikan penjelasan seperlunya dengan pihak yang bersangkutan (responden) yakni sumber data penelitian. Skala likert digunakan untuk mengukur sikap, pendapat dan persepsi seorang responden tentang fenomena yang dialami dalam organisasi koperasi. Variabel karakteristik organisasi diukur dengan 3 indikator: struktur organisasi, kejelasan tupoksi, dan pro pengembangan SDM. Variabel budaya organisasi diukur dengan 2 indikator: sistem nilai organisasi dan taat aturan. Variabel komitmen manajerial diukur dengan 3 indikator: kejelasan visi dan misi, konsistensi dalam kinerja, dan perhatian pada anggota. Variabel kepercayaan anggota diukur dengan 2 indikator: loyalitas dan kepatuhan pada aturan organisasi. Variabel partisipasi anggota diukur dengan 3 indikator: kemauan dalam menambah simpanan sukarela, keikutsertaan dalam pengambilan keputusan koperasi, dan mempromosikan koperasi. Variabel kinerja koperasi diukur dengan 4 indikator: Sisa Hasil Usaha (SHU), peningkatan jumlah anggota, tertib organisasi, dan penegakkan disiplin.

\section{Analisis Penelitian Dan Pembahasan}

\subsection{Hasil Uji Asumsi SEM}

Hasil pengujian validitas indikator dari semua variabel bebas tidak menunjukkan adanya variabel yang tidak valid. Selanjutnya, hasil pengujian validitas indikator pada variabel terikat juga tidak menunjukkan adanya indikator variabel yang tidak valid. Hal ini dikarenakan nilai signifikan lebih kecil dari 5\%, sehingga dinyatakan bahwa semua variabel penelitian baik bebas maupun terikat telah valid.

Variabel-variabel endogen baik reliabilitas menurut ukuran CR maupun AVE telah memenuhi syarat ketentuan yang ditetapkan. Hasil uji reliabilitas AVE juga telah memenuhi batas kritis yang ditetapkan yaitu 0.5 . 
PENGARUH KARAKTERISTIK ORGANISASI DAN BUDAYA ORGANISASI TERHADAP KOMITMEN MANAJERIAL, KEPERCAYAAN ANGGOTA DAN PARTISIPASI ANGGOTA SERTA DAMPAKNYA PADA KINERJA KOPERASI PADA KOPERASI KREDIT (CREDIT UNION) DI FLORES-Hyronimus Se

\subsection{Pengujian Hipotesis}

Pengujian hipotesis dilakukan pengujian terhadap koefisien-koefisien persamaan struktural dengan menspesifikasi tingkat signifikansi tertentu. Dalam penelitian ini digunakan $P=0.05$, sehingga critical ratio dari persamaan struktural harus $\geq 1.97$. Hasil pengujian hipotesis adalah sebagai berikut :

Tabel 4.1

Pengujian Hipotesis

\begin{tabular}{|c|c|c|c|c|c|c|}
\hline \multicolumn{3}{|c|}{ Path } & Beta & C.R & $p$ value & Keputusan \\
\hline $\mathrm{Y} 1$ & $<--$ & $\mathrm{X} 1$ & 0.299 & 3.952 & 0.000 & H0 ditolak \\
\hline $\mathrm{Y} 2$ & $<---$ & $\mathrm{X} 1$ & 0.341 & 4.418 & 0.000 & $\mathrm{H} 0$ ditolak \\
\hline $\mathrm{Y} 2$ & $<--$ & $\mathrm{X} 2$ & 0.234 & 3.078 & 0.002 & H0 ditolak \\
\hline Y3 & $<--$ & $\mathrm{X} 2$ & 0.300 & 3.582 & 0.000 & H0 ditolak \\
\hline Y3 & $<--$ & $\mathrm{X} 1$ & 0.269 & 3.309 & 0.000 & H0 ditolak \\
\hline $\mathrm{Y} 1$ & $<--$ & $\mathrm{X} 2$ & 0.338 & 4.31 & 0.000 & H0 ditolak \\
\hline Z & $<--$ & $\mathrm{Y} 1$ & 0.264 & 3.826 & 0.000 & H0 ditolak \\
\hline
\end{tabular}

\subsection{Uji Keseluruhan Model}

Tabel 4. 2

Evaluasi Kriteria Goodness- of-Fit

\begin{tabular}{|c|c|c|c|c|}
\hline No. & $\begin{array}{c}\text { Kriteria Goodnes- } \\
\text { of-Fit }\end{array}$ & Hasil & Cut-off Value & Evaluasi Model \\
\hline 1. & Chi-square $(\chi 2)$ & 115.149 & Diharapkan kecil & $\begin{array}{c}\text { Lebih Kecil } \\
\text { (Signifikan) }\end{array}$ \\
\hline 2. & Probability $(\rho)$ & 0.350 & $\geq 0.05$ & Fit \\
\hline 3. & CMIN/DF $(\chi 2 / d f)$ & 1.047 & $\begin{array}{c}\leq 5 \text { (Wheaton } \text { et al., 1977 } \\
\text { dalam Ghozali } 2008)\end{array}$ & Fit \\
\hline 4. & GFI & 0.945 & $\geq 0.90$ & Fit \\
\hline 5. & AGFI & 0.924 & $\geq 0.90$ & Fit \\
\hline 6. & RMSEA & 0.014 & $\geq 0,08$ & Fit \\
\hline 7. & CFI & 0.997 & $\geq 0.90$ & Fit \\
\hline 8. & TLI (NNFI) & 0.996 & $\geq 0.90$ & \\
\hline
\end{tabular}

Hasil goodness-of-fit diketahui bahwa nilai 115.149 dengan nilai Probability $(\rho)$ sebesar 0.350 yang menunjukkan bahwa model fit karena nilai Probability $(\rho) \geq 0.05$. Hasil goodness-of-fit juga diketahui bahwa nilai CMIN/DF $(\chi 2 / d f)$ sebesar 1.047 atau lebih kecil dari 5. Kecocokan model juga didukung oleh nilai GFI $=0.945$, AGFI $=$ 0.924, $\mathrm{CFI}=0.997$, dan TLI $(\mathrm{NNFI})=0.996$ berada diatas 0.90 dan RMSEA sebesar 0.014 yang berarti $\leq 0,08$ sehingga model dikatakan cocok karena seluruh nilai goodness-of-fit baik dan sesuai dengan cut of value. 


\section{Kesimpulan dan Saran}

\subsection{Kesimpulan}

Berdasarkan hasil analisis data dan pengujian hipotesis yang diperoleh, maka peneliti mengambil beberapa simpulan guna menjawab rumusan masalah dan hipotesis yang telah dikemukakan sebelumnya. Simpulan yang dapat diambil terdiri dari: 1). Karakteristik organisasi mempunyai pengaruh yang signifikan terhadap komitmen manajerial. Makin rampingnya struktur organisasi, kejelasan tugas pokok dan fungsi, dan pro pengembangan sumber daya manusia akan meningkatkan komitmen manajerial, 2). Karakteristik organisasi mempunyai pengaruh signifikan terhadap kepercayaan anggota. Makin baiknya sistem nilai organisasi dan taat aturan maka akan meningkatkan kepercayaan anggota, 3). Karakteristik organisasi mempunyai pengaruh signifikan terhadap partisipasi anggota. Adanya kemauan dalam menambah simpanan sukarela, keikutsertaan dalam pengambilan keputusan koperasi dan ikut mempromosikan koperasi maka akan mempertinggi tingkat partisipasi anggota, 4). Budaya organisasi mempunyai pengaruh signifikan terhadap komitmen manajerial. Makin rampingnya kejelasan visi dan misi, konsistensi dalam kinerja, dan perhatian pada anggota maka akan meningkatkan komitmen manajerial, 5). Budaya organisasi mempunyai pengaruh signifikan terhadap kepercayaan anggota. Makin tingginya loyalitas dan kepatuhan pada organisasi maka akan mempertinggi tingkat kepercayaan anggota, 6). Komitmen manajerial mempunyai pengaruh signifikan terhadap kinerja koperasi. Meningkatnya jumlah sisa hasil usaha, meningkatnya jumlah anggota, tertib organisasi, dan penegakkan disiplin akan berdampak pada peningkatan kinerja koperasi.

\subsection{Saran}

Berdasarkan simpulan yang diuraikan diatas, maka peneliti akan memberikan saran dan masukan yang perlu diperhatikan oleh pihak koperasi kredit (credit union) di Flores guna perbaikan kedepannya, saran tersebut terdiri dari: 1) Diharapkan pemerintah daerah atau Dinas Koperasi dan UKM Provinsi Nusa Tenggara Timur dalam apaya meningkatkan kinerja kopdit yang ada, disarankan untuk memperkuat komitmen manajerial melalui kegiatan pelatihan yang terprogram serta mengintensifkan kegiatan memonitoring dan evaluasi koperasi secara rutin. 
Selanjutnya untuk meningkatkan partisipasi anggota kopdit, disarankan Dinas Koperasi dan UKM Provinsi Nusa Tenggara Timur meningkatkan program sosialisasi koperasi kepada masyarakat dalam bentuk penyuluhan dan pembuatan brosur tentang proses dan manfaat koperasi, 2) Kepada pihak pengurus, pengawas dan pengelola kopdit, untuk meningkatkan kinerja koperasi disarankan agar dalam mengelola koperasi dilaksanakan secara profesional, transparan, bertanggung jawab, dan adil guna meningkatkan kepercayaan dan partisipasi anggota, dan 3) Kepada peneliti selanjutnya, disarankan untuk mengembangkan variabel-variabel lain yang berkontribusi terhadap peningkatan kinerja koperasi, baik koperasi kredit maupun koperasi lainnya.

\section{Daftar Pustaka}

Abdullah, M. Faisal. (2005). "Dasar-dasar Manajemen Keuangan Edisi Kedua Cetakan Kelima." Malang: Penerbitan Universitas Muhammadiyah.

Armstrong, M. (1994). Manajemen Sumber Daya Manusia: A Handbook Of. Human Resource.

Dakurah, H. A. (2005). First Draft: Attitudes Towards and Satisfaction with Credit Unions in Alberta . A Regression and Scale Analysis . Draft Paper By. 1-36.

Djastuti, I. (2010). the Influence of Job Characteristics. 3(2), 145-166.

Ehtesham, U. M., Muhammad, T. M., \& Muhammad, S. A. (2011). Relationship between Organizational Culture and Performance Management Practices : A Case of University in Pakistan. Journal of Competitiveness |, 4, 78-86.

Ekonomi, F., \& Udayana, U. (2014). ANALISIS KINERJA BERBASIS BALANCED SCORECARD PADA KOPERASI XYZ

Ferdinand, A. (2014). Metode Penelitian Manajemen Pedoman Penelitian Untuk Penulisan Skripsi, Tesis, dan Disertasi Ilmu Manajmen (lima). Jakarta: Badan Penerbit Universitas Diponegoro.

Hofestede, G., Neuijeen, B., Ohayv, D. D., \& Sanders, G. (1990). Measuringe Organiosational Cultures: A Qulaitative Study across Tenty Cases. Admi, 35, 286-316.

In, S., Fulfillment, P., The, O. F., Of, R., \& Of, M. (2008). Organizational Culture and Employee Commitment : a Case Study. November, 1-121.

Imam, G. (2005). Aplikasi analisis multivariate dengan program SPSS. Semarang: Badan Penerbit Universitas Diponegoro.

Mayer, R. C., Davis, J. H., \& Schoorman, F. D. (1995). An integrative model of organizational trust. Academy of management review, 20(3), 709-734. 
MBOKA, O. (2014). SOCIETIES ( SACCOs ) ON THE GROWTH SUSTENANCE OF SMALL BUSINESSES IN TANZANIA : THE CASE OF MBEYA CITY A DISSERTATION SUBMITTED IN PARTIAL FULFILLMENT FOR THE REQUIREMENTS FOR THE DEGREE OF MASTERS OF BUSINESS. (1945). 193-203.

Munandar, A. S., Sjabadhyni, B., \& Wutun, R. P. (2004). Peran budaya organisasi dalam peningkatan unjuk kerja perusahaan. Depok: Penerbit PIO Fakultas Psikologi UI.

Muthyalu, M. (2013). The Factors that Influence the Participation of Cooperative Members in the Agricultural Input and Output Marketing - A Case Study of Adwa District, Ethiopia. Journal of Business Management \& Social Sciences Research, 2(4), 121-130.

Philip, T., Bryon, P. A., Philippe, N., Souillet, G., Freycon, F., Gérard-Marchant, R., \& Brunat-Mentigny, M. (1980). [Anatomo-clinical characterization of Burkitt's lymphoma in France.

Schein, E. H. (2010). Organizational culture and leadership

Sukidjo. (2008). Membangun Citra Koperasi Indonesia - 193-203. 